\title{
Plastics in Total Knee Replacement: Processing to Performance
}

\author{
Naga Cheppalli ${ }^{1}$, Sreenivasulu Metikala ${ }^{2}$, Benjamin S. Albertson ${ }^{3}$, Kenneth Yaw ${ }^{4}$ \\ 1. Orthopaedics, Veteran Affairs (VA) Hospital/University of New Mexico Hospital, Albuquerque, USA 2. Orthopaedics, \\ Virginia Commonwealth University Health System, Richmond, USA 3. Orthopaedics \& Rehabilitation, University of \\ New Mexico Health Sciences Center, Albuquerque, USA 4. Orthopaedics, New Mexico Veteran Affairs (VA) Health Care \\ System, Albuquerque, USA
}

Corresponding author: Sreenivasulu Metikala, smetikala@gmail.com

\begin{abstract}
Polyethylene (PE) is the key component of total knee replacement (TKR). The wear of polyethylene, a common cause of revision surgeries, depends on multiple factors. The mechanical properties, wear characteristics, and oxidative resistance of PE can be manipulated by the techniques of processing, sterilization, and packaging methods. This article describes the making of conventional and cross-linked poly, packaging, sterilization, processing techniques, and a summary of commercially available plastics and their rationale in TKR including the latest advances.
\end{abstract}

Categories: Medical Education, Orthopedics, Other

Keywords: polyethylene, crosslinked, knee arthroplasty, wear, sterilization, packaging, oxidation, fatigue, antioxidant, vitamin e

\section{Introduction And Background}

Polyethylene (PE) is an integral part of total knee replacement (TKR) and has undergone significant changes in the last three decades. PE wear is one of the common causes of revision knee replacement [1-3]. Multiple factors predispose PE to wear. Some of them are methods of PE processing (packaging, sterilization), type of implants, the thickness of the PE, locking mechanisms, surface roughness of the metallic tibial tray, surface contour of PE and area of articulation with the femoral component, types of movements between the bearing surfaces (rolling, sliding, and rotational motion), presence of third body wear, alignment inaccuracies and patient-related factors like body mass index (BMI), and patient activity level $[4,5]$. Further, various PE designs such as cruciate-retaining, posterior-stabilized, medial congruent, medial pivot, anterior stabilized, constrained poly with a longer and wider post, bicruciate stabilized components can influence the mechanical forces transmitted at the area of contact and contribute to wear $[6,7]$.

This article focuses on 1) processing of PE, 2) packaging and sterilization techniques, 3) mechanical and wear properties of the final product, and 4) product options available from different implant manufacturers.

Review began 01/03/2021 Review ended 01/22/2021 Published 01/28/2021

(๑) Copyright 2021 Cheppalli et al. This is an open access article distributed under the terms of the Creative Commons Attribution License CC-BY 4.0., which permits unrestricted use, distribution, and reproduction in any medium, provided the original author and source are credited.

\section{Review}

\section{Making of conventional polyethylene (CPE)}

Raw Material

PE is a polymer of ethylene consisting of as many as 200,000 ethylene repeat units. Ethylene is polymerized in the presence of catalysts to make ultra-high molecular weight polyethylene (UHMWPE), which is commercially produced as resin powder. There are three types of resins labeled as GUR 1020 (Type 1), GUR 1050 (Type 2), and $1900 \mathrm{H}$ (Type 3). This classification is based on the presence of impurities such as titanium, aluminum, chlorine, calcium, as well as storage and handling properties. The acronym GUR stands for Granular-UHMWPE-Ruhrchemie, which came from Celanese, the first company to manufacture UHMWPE for Orthopedics. Currently, GUR 1020 and GUR 1050 powders are routinely used, although most manufacturers prefer the former type because of its higher ductility and impact strength. Since 2002, the resin $1900 \mathrm{H}$ (type 3) has been withdrawn from the market.

\section{Processing}

The chosen resin powder is consolidated into rods/sheets from which final implants are made. Historically, this conversion is done by compression molding (popular in Europe), ram extrusion (popular in the United States), hot isostatic pressing (used by Biomet, Inc, Warsaw, IN), or direct compression molding (DCM), which is also known as net shape compression molding where the resin powder is directly converted into the finished or semi-finished product [8]. Unfinished products are machined into the desired shapes (Figure 1). 


\section{Cureus}

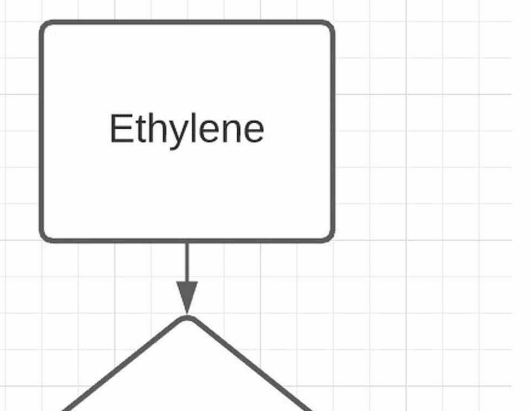

UHMWPE/resin

powder

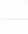

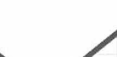

Rods/Sheets

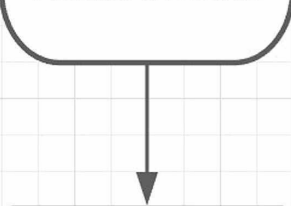

Final

Implants
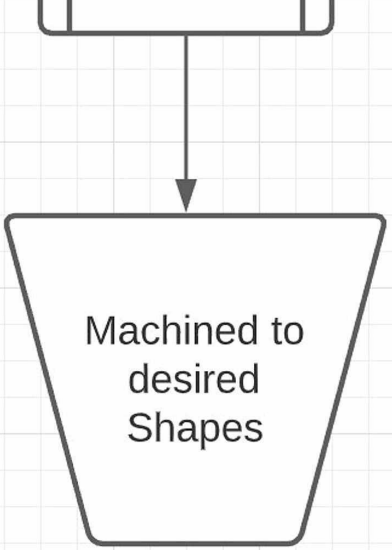

FIGURE 1: Flow diagram of the making of conventional polyethylene (CPE)

Non-articulating surfaces of the components are machined to accommodate the locking mechanism. Machining, however, may cause microscopic surface irregularity, which can contribute to future wear. Therefore, the speed of milling devices and the heat produced during the machining process are highly regulated to minimize deteriorating effects on PE. Thus, the resin type, conversion method, and machining to the final product have individual effects on the physical properties and wear characteristics of the final plastic product. Since there has been no consensus to determine the best plastic production process in the orthopedic industry, the implant companies have sought their own strategies for processing UHMWPE.

Packaging and Sterilization

Once final implants are made, packaging and sterilization of PE are the crucial steps that can significantly 


\section{Cureus}

affect PE's wear properties. Basically, there are five main methods of sterilization (Table 1).

\begin{tabular}{|c|c|c|}
\hline Sterilization Process & Packaging Type & Radiation Dose (Mrd) \\
\hline Gamma air & Gas permeable & $2.5-4.0$ \\
\hline Gamma inert & Oxygen barrier packaging/ reduced oxygen atmosphere & $2.5-4.0$ \\
\hline Electron beam (E-beam) & Reduced oxygen atmosphere & $2.5-4.0$ \\
\hline Ethylene Oxide & Gas permeable & None \\
\hline Gas plasma & Gas permeable & None \\
\hline
\end{tabular}

\section{TABLE 1: Summary of various sterilization processes}

Mrd: megarads

Radiation techniques include gamma irradiation and electron beam (E-beam). Ethylene Oxide (EtO) and gas plasma (GP) are the non-radiation sterilization methods. In the past, sterilization was done by gamma irradiation in the presence of air. This method, however, had resulted in the production of innumerable free radicals that typically react with oxygen causing PE chain scission and significant oxidative wear. In an attempt to minimize such free radical production, sterilization has now been performed in the absence of air or near-vacuum (Depuy Orthopedics, Warsaw, IN) or in the presence of inert gases like Nitrogen (Stryker Orthopedics, Mahwah, NJ and Zimmer, Inc, Warsaw, IN) or Argon (Biomet). Also, the final plastic is wrapped using barrier packaging materials which in turn helps to prevent oxidation. However, PE chain breakage can still happen in the long-term because of the production of residual free radicals which are responsible for ongoing oxidative damage. The generation of such a small quantity of free radicals is inevitable despite meticulous processing techniques, which is considered as an acceptable minimum level. EtO is an alternative sterilization method to radiation, which totally eliminates oxidative damage. While this method can better preserve all the properties of PE, handling EtO is expensive and time-consuming. Recently, GP sterilization is another alternative that relies on ionized gas. It has been showing promising results without leaving any toxic residues. Surgeons should be aware that the shelf life of PE depends on the methods of packaging and sterilization. At this time, there is no consensus in the United States regarding the acceptable shelf life. Whereas in Europe, a standard practice of five years of shelf life has been adopted [9]. Given that sterilization by EtO or GP does not produce any free radicals, the longer shelf life of more than five years may be justifiable. An irradiated plastic either by gamma or E-beam necessitates gas barrier packaging methods to prevent oxidation, while gas permeable packaging is acceptable for EtO and GP sterilization techniques [10].

\section{Cross-linked polyethylene (XLPE)}

The next successful attempt to improve the mechanical properties of PE, particularly the wear resistance, is achieved by cross-linking adjacent chains through higher doses of irradiation, producing XLPE (Figure 2).
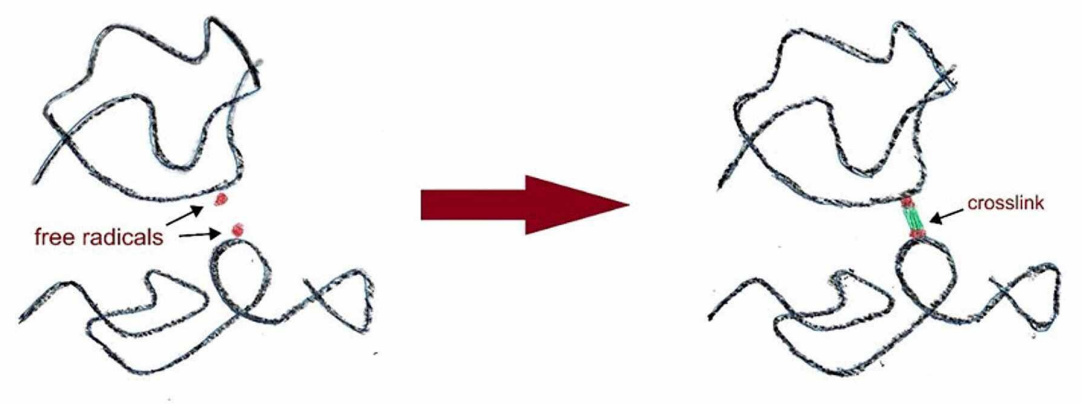

FIGURE 2: The process of cross-linking of adjacent chains

Initially, cross-linking was induced by a single sterilization dose (2.5 to $4.0 \mathrm{Mrd}$ ), which substantially enhanced wear performance. However, it led to a reduction in fatigue crack propagation (FCP) resistance, 
ultimate tensile strength, elongation at break values, and impact toughness [10]. The XLPE plastics have been in widespread use since the late 1990s [11]. Further increasing the radiation dose (5 to $10 \mathrm{Mrd}$ ), results in radical species that react with chain imperfections leading to polymer chain cross-linking with stable C-C chemical bonds. It theoretically increases the molecular mass to infinity, thus producing highly cross-linked polyethylene (HXLPE), which came to the market in 1998 [8].

Both gamma and E-beam radiation are used to cross-link PE. Gamma radiation generally uses Cobalt-60 as the source of radiation. While gamma radiation can penetrate through resin powder, the penetration of Ebeam radiation is limited by its kinetic energy [9]. Nonetheless, there is no significant difference in the formation of macro radicals between these two methods. Although higher radiation doses can significantly improve wear resistance, it results in brittleness of plastic and poor mechanical properties. Also, the wear particles generated from HXLPE can be smaller and biologically more active than non-irradiated ones $[12,13]$. Thermal treatment, either by remelting or annealing, can improve some of these characteristics, as described below.

Thermal Treatment - Remelting

In an effort to absorb residual free radicals and improve oxidation properties, the irradiated HXLPE is remelted above its melting temperature (greater than 150 degrees Celsius), which is typically done before the plastic is machined into the final product. Although such post-irradiation remelting likely increases the long-term oxidation resistance, it further compromises the mechanical properties due to the microstructure's alteration, decreased crystallinity, and low FCP resistance [14]. Few cases of tibial post fractures have been reported with remelted PE [15].

Thermal Treatment - Annealing

Annealing has been introduced to impart higher mechanical properties, where reheating of HXLPE is done close to but below its melting temperature. This process retains the crystallinity of plastic and improves fatigue performance while preserving the wear characteristics [5]. However, the annealed plastic has not proven to be as effective as the remelted poly in terms of reducing the quantity of residual free radicals. Consequently, this led to increased oxidative wear and overall deterioration of mechanical properties when subjected to the accelerated aging test. For these reasons, the annealed PE never took off commercially.

Sequentially Irradiated and Annealed Polyethylene

It is a unique process where compression-molded GUR 1020 resin undergoes sequential irradiation and annealing to produce a particular type of HXLPE, the X3 (Stryker Orthopaedics, Mahwah, NJ). The process of sequential irradiation happens in three different cycles, with each cycle set at a radiation dose of $3 \mathrm{Mrd}$ followed by annealing for 8 hours at 130 degrees C. Following this process, the material's outer 1-3 mm is removed, the component is then machined and packaged for GP sterilization. The cumulative radiation dose thus becomes $9 \mathrm{Mrd}$. The X3 is designed to retain mechanical properties while reducing the proportion of free radicals. X3 poly was initially introduced for hips in 2005, followed by knees in 2008. A knee simulator study comparing six poly designs demonstrated the lowest wear rates with X3 poly [16]. However, early failures with fractures and oxidation damage have been reported with this design affecting mainly the posteromedial and lateral borders [17]. Although there are no long term data using X3 in TKA, the short term studies have demonstrated superior wear characteristics $[18,19]$.

HXLPE can be classified into first and second generation based on processing technique. When subjected to post-irradiation thermal treatment, it is considered the first generation. In comparison, sequential irradiation-annealing or addition of antioxidants is considered to be the second-generation category.

\section{Antioxidants}

To overcome long-term oxidation while preserving the mechanical properties of HXLPE, the manufacturers have begun the addition of antioxidants, specifically Vitamin E (VitE), a natural antioxidant that has been used in food packaging since 1980 [8]. There are two methods of incorporating VitE. The first method includes blending VitE into resin powder (in concentrations ranging from 1000-8000 ppm) even before consolidation and irradiation. Studies demonstrated that this method prevents in-vivo oxidation, accelerated aging, and improves wear characteristics but at the expense of decreased cross-linking efficiency [20]. For that reason, an alternative method of VitE diffusion (soaking or infusion) into poly following radiation has been introduced.

VitE-coated blocks are placed into an inert oven and homogenized (baked) at $120^{\circ} \mathrm{C}$ until the vitamin diffuses through the block's thickness. This technique resulted in higher oxidation resistance in vitro, along with ultra-low wear, and retained mechanical strength. There is a theoretical concern that with progressive wear, VitE may elute into the joint and get absorbed systemically. To prevent such elution, VitE is bonded to PE by covalent bonds (grafting). Even in this hypothetical situation, the amount of VitE that diffuses into the system is thought to be too low to cause any cellular cytotoxic effects. In an in vitro study, VitE poly 
demonstrated decreased bacterial adherence (Staphylococcus epidermis and S. aureus) $[21,22]$. Overall, preclinical studies have shown promising improvements in fatigue strength when doped with VitE while maintaining the wear properties and oxidation resistance comparable to irradiated and remelted HXLPE [23]. In vitro studies showed that VitE poly has five times greater ultimate strength after four weeks of accelerated aging test and up to an $86 \%$ lower wear rate than CPE [24]. Further, lower rates of bone resorption and inflammatory fibrous tissue were noted with VitE poly than HXLPE $[25,26]$. In literature, fracture of VitE poly has been reported in THR but not in TKR [27]. However, there are no midterm or long-term studies available on the use of VitE poly in TKR.

Table 2 illustrates the evolution of plastics and the differences in their characteristics.

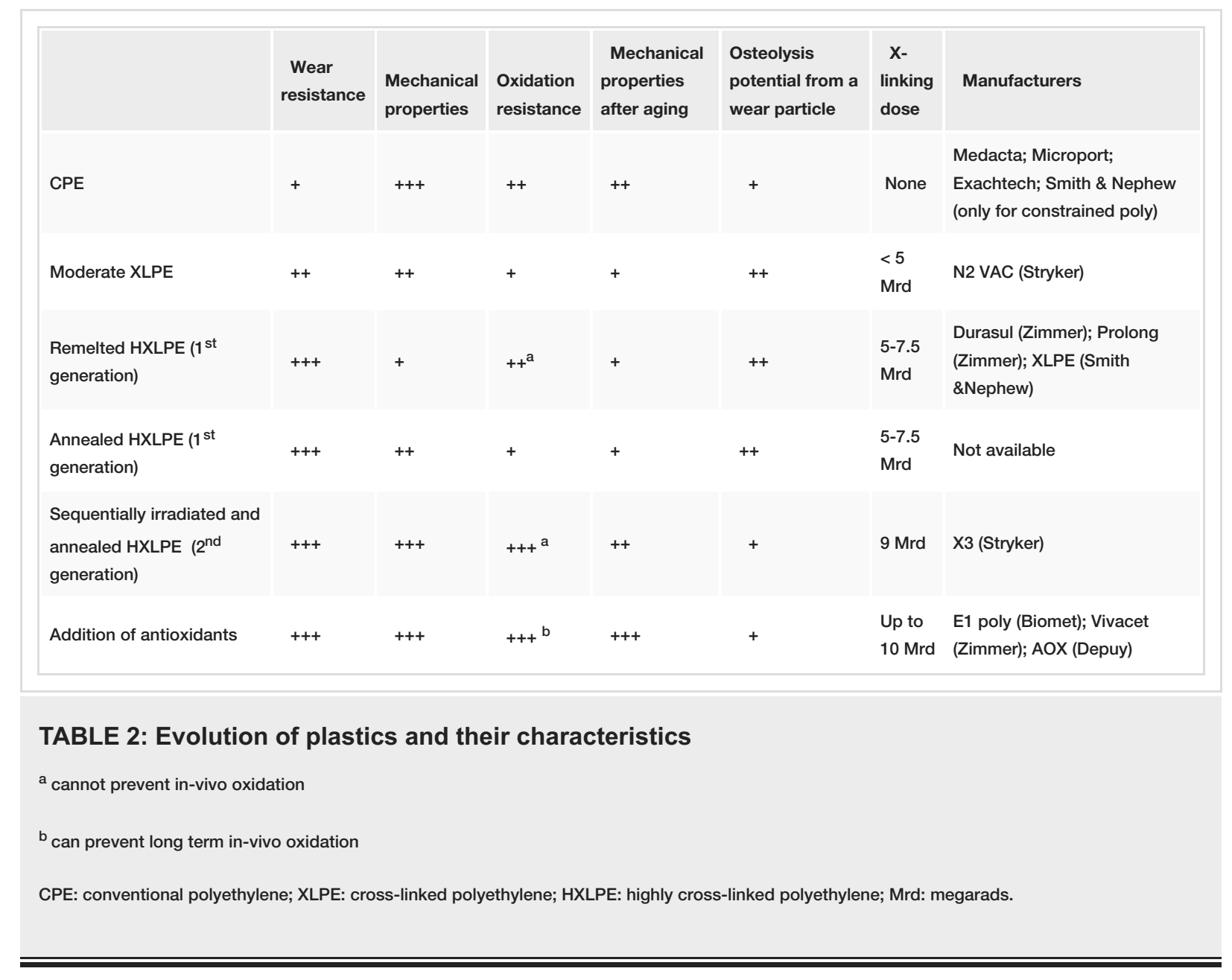

\section{Using CPE for TKA}

While most companies have adopted newer technology, some still market CPE (non-cross linked) due to the concerns that cross-linking leads to inferior mechanical properties. Thermal treatment of irradiated HXLPE further compromises the mechanical properties. As discussed earlier, remelted HXLPE has good oxidation and wear performances but possesses reduced crystallinity and lower fatigue strength. On the other hand, annealed HXLPE has fair wear and fatigue performances but poor oxidation resistance [28,29]. Further, it has been demonstrated that wear particles induced by HXLPE and CPE have different biological host responses [30-32]. In an animal model, a greater risk of particle-induced osteolysis and heightened inflammatory response was observed in the HXLPE group compared to CPE and VitE poly [12]. Finally, the proponents of $\mathrm{CPE}$ argue that the mode of poly failure is different in THA compared to TKA. The most common cause of PE failure in TKA is delamination [33] while adhesive or abrasive wear is the common cause in THA due to better conformity and even stress distribution [16,33]. For these reasons, some manufacturers prefer the preservation of mechanical properties to wear properties in an attempt to avoid such delamination.

Table 3 depicts a summary of various commercially available plastics \& their processing methods for TKR.

\begin{tabular}{|l|l|l|l|l|}
\hline Manufacturer & $\begin{array}{l}\text { Plastic } \\
\text { name }\end{array}$ & Resin & Processing & Sterilization \\
\hline
\end{tabular}




\section{Cureus}

\begin{tabular}{|c|c|c|c|c|c|}
\hline $\begin{array}{l}\text { Zimmer } \\
\text { (Persona) }\end{array}$ & $\begin{array}{l}\text { Vivacet- } \\
\text { E }\end{array}$ & $\begin{array}{l}\text { GUR } \\
1020\end{array}$ & $\begin{array}{l}10 \mathrm{Mrd} \text {; E-beam at elevated temperature; No further heat } \\
\text { treatment; Vit E is pre-blended with resin }\end{array}$ & EtO & Air \\
\hline Zimmer (Nexgen) & Prolong & $\begin{array}{l}\text { GUR } \\
1020 \\
\text { GUR } \\
1050\end{array}$ & 6.5 Mrd; E-beam at elevated temperature; Remelted & $\begin{array}{l}\text { Gas plasma/ } \\
\text { EtO }\end{array}$ & $\begin{array}{l}\text { Nitrogen/ High } \\
\text { oxygen barrier }\end{array}$ \\
\hline $\begin{array}{l}\text { Zimmer (Natural } \\
\text { Knee 2) }\end{array}$ & Durasul & $\begin{array}{l}\text { GUR } \\
1050\end{array}$ & 9.5 Mrd; E-beam; Remelted & EtO & Nitrogen \\
\hline $\begin{array}{l}\text { Biomet } \\
\text { (Vanguard) }\end{array}$ & E1 Poly & $\begin{array}{l}\text { GUR } \\
1020\end{array}$ & $\begin{array}{l}10 \text { Mrd; Gamma radiation; No heat treatment; VitE infused } \\
\text { after cross-linking }\end{array}$ & $\begin{array}{l}3 \mathrm{Mrd} \text {; } \\
\text { Gamma } \\
\text { radiation in } \\
\text { Argon }\end{array}$ & $\begin{array}{l}\text { Argon flushed/ } \\
\text { Near-vacuum } \\
\text { sealed }\end{array}$ \\
\hline Biomet & $\begin{array}{l}\text { Arcom } \\
X L\end{array}$ & $\begin{array}{l}\text { GUR } \\
1050\end{array}$ & 5Mrd; Gamma radiation & $\begin{array}{l}\text { Gamma } \\
\text { radiation in } \\
\text { Argon }\end{array}$ & $\begin{array}{l}\text { Inert } \\
\text { environment }\end{array}$ \\
\hline Biomet & $\begin{array}{l}\text { Arcom } \\
\text { (R) }\end{array}$ & $\begin{array}{l}\text { GUR } \\
1050\end{array}$ & No X-linking; No thermal treatment & $\begin{array}{l}\text { Gamma } \\
\text { radiation }\end{array}$ & $\begin{array}{l}\text { Inert } \\
\text { environment }\end{array}$ \\
\hline Stryker (Triathlon) & $\mathrm{X} 3$ & $\begin{array}{l}\text { GUR } \\
1020\end{array}$ & $\begin{array}{l}\text { Sequential Gamma irradiation at room temp; } 3 \mathrm{Mrd} \times 3 \\
\text { times (total dose: } 9 \mathrm{Mrd} \text { ); Annealed at } 30^{\circ} \mathrm{C} \text { after each } \\
\text { cycle }\end{array}$ & Gas plasma & $\begin{array}{l}\text { Nitrogen/ } \\
\text { Vacuum } \\
\text { sealed }\end{array}$ \\
\hline $\begin{array}{l}\text { Stryker } \\
\text { (Scorpio/NRG) }\end{array}$ & N2VAC & $\begin{array}{l}\text { GUR } \\
1020\end{array}$ & Conventional; No radiation & $\begin{array}{l}3 \mathrm{Mrd} \text {; } \\
\text { Gamma } \\
\text { radiation in } \\
\mathrm{N} 2\end{array}$ & Barrier \\
\hline Depuy (Attune) & AOX & $\begin{array}{l}\text { GUR } \\
1020\end{array}$ & $\begin{array}{l}8.5 \text { Mrd; Gamma radiation at room temperature; No heat } \\
\text { treatment; Covernox (Hindered Phenol. } 075 \% \text { and few } \\
\text { more antioxidants) in resin }\end{array}$ & $\begin{array}{l}\text { 3Mrd; } \\
\text { Gamma } \\
\text { radiation }\end{array}$ & Vacuum foil \\
\hline DePuy Sigma & XLK & $\begin{array}{l}\text { GUR } \\
1020\end{array}$ & $\begin{array}{l}5 \text { Mrd: Gamma radiation at room temperature; Remelted at } \\
155^{\circ} \mathrm{C} \text { for } 24 \text { hours and then annealed at } 120^{\circ} \mathrm{C} \text { for } 24 \\
\text { hours }\end{array}$ & $\begin{array}{l}\text { Gamma } \\
\text { radiation/ } \\
\text { Gas plasma }\end{array}$ & Vacuum foil \\
\hline Depuy LCS & XLK & $\begin{array}{l}\text { GUR } \\
1020\end{array}$ & 5 Mrd; Gamma radiation; Remelted & Gas plasma & Vacuum foil \\
\hline Depuy & GVF & $\begin{array}{l}\text { GUR } \\
1020\end{array}$ & No X-linking; No thermal treatment & $\begin{array}{l}\text { Gamma } \\
\text { radiation }\end{array}$ & Vacuum foil \\
\hline $\begin{array}{l}\text { Smith \& } \\
\text { Nephew (Journey } \\
1 \text { and 2) (Legion) }\end{array}$ & XLPE & $\begin{array}{l}\text { GUR } \\
1020\end{array}$ & $\begin{array}{l}7.5 \mathrm{Mrd} \text {; Gamma radiation at room temperature; Remelted } \\
\text { at } 147^{\circ} \mathrm{C} \text { for at least } 5 \text { hours }\end{array}$ & EtO & Barrier \\
\hline $\begin{array}{l}\text { Smith \& Nephew } \\
\text { (Genesis II) }\end{array}$ & XLPE & $\begin{array}{l}\text { GUR } \\
1050\end{array}$ & No radiation; No thermal treatment & Gas plasma & Barrier \\
\hline $\begin{array}{l}\text { Advance } \\
\text { medicals } \\
\text { Microport }\end{array}$ & $\begin{array}{l}\text { Duramer } \\
-1\end{array}$ & $\begin{array}{l}\text { GUR } \\
1020\end{array}$ & No radiation; No thermal treatment & EtO & N/A \\
\hline Medacta & GMK & $\begin{array}{l}\text { GUR } \\
1020\end{array}$ & No radiation; No thermal treatment & EtO & $\begin{array}{l}\text { Gas } \\
\text { permeable }\end{array}$ \\
\hline Aesculap & $\begin{array}{l}\text { Beta - } \\
\text { PE }\end{array}$ & $\begin{array}{l}\text { GUR } \\
1020\end{array}$ & X-linking with beta radiation; No heat treatment & N/A & Inert \\
\hline Conformis & iPoly XE & $\begin{array}{l}\text { GUR } \\
1020\end{array}$ & $\begin{array}{l}10 \text { Mrd; E-beam at elevated temperature; No heat } \\
\text { treatment; Mechanically annealed; VitE blended }\end{array}$ & Gas plasma & N/A \\
\hline Exachtech & Logic & $\begin{array}{l}\text { GUR } \\
1020\end{array}$ & 6.5 Mrd; E-beam at $125^{\circ} \mathrm{C}$; Remelted & $\begin{array}{l}\text { Gamma } \\
\text { radiation }\end{array}$ & N/A \\
\hline Arthrex & E-CIMA & $\begin{array}{l}\text { GUR } \\
1020\end{array}$ & 9.5 Mrd; E-beam; VitE blended at raw material state & $\begin{array}{l}\text { Gamma } \\
\text { radiation }\end{array}$ & Vacuum foil \\
\hline
\end{tabular}




\section{Cureus}

TABLE 3: Summary of commercially available plastics for total knee replacement

VitE: vitamin E; Mrd: megarad; EtO: ethylene oxide; XLPE: cross-linked polyethylene; N/A: not available.

\section{Clinical studies}

Existing short and midterm studies demonstrate no differences in revision rates between XLPE and CPE in TKA [32,34]. However, one long-term study (Australian joint registry) showed significantly lower revision rates at a 10-year follow-up with XLPE than CPE (3.5\% versus 5.8\%) [35].

\section{PE particulate studies}

Osteolysis depends on the host response to the amount, size, shape, and quality of PE particles generated from wear. More elongated particles in large quantities tend to produce a greater inflammatory response $[36,37]$. The particle size less than $0.05 \mu \mathrm{m}$ or longer than $10 \mu \mathrm{m}$ fails to elicit an inflammatory response $[12,38]$. The typical size of wear particles in TKA is approximately $1 \mu \mathrm{m}$. Notably, the wear particles from irradiated HXLPE are smaller and biologically more active than from non-irradiated ones. However, periprosthetic osteolysis is not commonly observed because of an overall reduction in the quantity of wear production in HXPLE compared to CPE [34,39].

\section{Registry studies}

Table 4 summarizes joint replacement registry studies and the revision rates with CPE and HXLPE $[35,40-$ 42].

\begin{tabular}{|c|c|c|c|c|c|}
\hline Study & Procedures & Revision rate with CPE & $\begin{array}{l}\text { Revision rate with } \\
\text { HXLPE }\end{array}$ & $\begin{array}{l}\text { Antioxidants } \\
\text { infused }\end{array}$ & Registry \\
\hline Inacio & 62,177 & $2.2 \%$ at 3 years & $2.1 \%$ at 1.8 years & N/A & Not listed \\
\hline Paxton & 77,084 & $2.7 \%$ at 5 years & $3.1 \%$ at 5 years & $\mathrm{N} / \mathrm{A}$ & $\begin{array}{l}\text { Kaiser Permanante Total Joint } \\
\text { Replacement Registry }\end{array}$ \\
\hline $\begin{array}{l}\text { De } \\
\text { Steiger }\end{array}$ & 386,104 & $5.8 \%$ at 10 years & $3.5 \%$ at $10 \mathrm{yr}$ & N/A & $\begin{array}{l}\text { Australian Orthopedic Association } \\
\text { National Joint Replacement Registry }\end{array}$ \\
\hline Partridge & 550,658 & $\begin{array}{l}0.29 \text { aseptic revisions } \\
\text { per } 100 \text { component } \\
\text { years }\end{array}$ & $\begin{array}{l}0.38 \text { aseptic revisions } \\
\text { per } 100 \text { component } \\
\text { years }\end{array}$ & N/A & $\begin{array}{l}\text { National Joint Registry (NJR) for } \\
\text { England, Wales, and Northern Ireland } \\
2003-14\end{array}$ \\
\hline
\end{tabular}

\section{TABLE 4: Registries data and revision rates}

CPE: conventional polyethylene; HXLPE: highly cross-linked polyethylene; N/A: not available.

\section{Cost}

The implant's cost is not standardized and therefore varies significantly among different hospitals, geographic regions, and manufacturers. Given these constraints, it is not easy to pinpoint the exact cost difference between HXLPE and CPE. Data from one hospital suggests that HXLPE inserts cost approximately 150 USD more than CPE, while others estimate this difference to be even higher [43]. With the advent of the bundled payment system in joint replacements, an emphasis has been placed on providing the highest quality care, with quality measured as value/cost. It remains unknown if HXLPE increases the value to TKA sufficient enough to warrant the increased cost compared to CPE. It is still to be determined if it is costeffective to use HXLPE in only younger patients to avoid future revisions [44].

\section{What's new}

A wide range of fillers have been used to enhance PE's mechanical and lubrication properties. Some of them are carbon nanofibers (CNFs), carbon nanotubes (CNTs), graphene, and hard particles like titanium, zirconium, quartz, natural coral, platinum-zirconium quasicrystal, etc. [45-48]. Surface modifications of PE can also be performed using zirconium carbon nitride ( $\mathrm{ZrCxN1} 1-\mathrm{x})$ coating embedded with silver nanoparticles or hydrogenated diamond-like carbon (DLCH) coating. They have shown good performance on the wear resistance, hardness, and biocompatibility. The other techniques, like ion beam surface modification, photolithography, nanoimprint lithography, and laser surface texturing, are also being explored in the industry [44]. 
While we look optimistically at the future, we should never forget our past failures where several attempts have been made to reinforce PE's mechanical properties. A few unsuccessful attempts are carbon-fiberreinforced poly (CFR-UHMWPE) marketed as Poly II (Zimmer) and Hylamer (Depuy). The Poly II was introduced in 1970 but was discontinued due to the rupture of the surface fibers and reduced crack resistance than the virgin UHMWPE [35]. In the late 1980s, high-pressure recrystallized poly was released as Hylamer, which demonstrated higher susceptibility to oxidation than the virgin UHMWPE. Its poor performance was attributed to gamma sterilization in the air and fell out of favor in the late 1990s with the development of XLPE [49].

\section{Conclusions}

There are several ways to process PE and manipulate their mechanical properties, wear characteristics, and oxidative resistance. An ideal PE's properties include strong resistance to wear, oxidation, and FCP and should retain these properties in-vivo for the long-term. Wear resistance is improved by crosslinking the PE, which is accomplished by higher doses of radiation (Gamma or E-beam). However, such radiation doses generate more free radicals that promote long-term oxidative degradation of PE. Post-irradiation thermal treatment (first-generation XLPE) can quench these free radicals improving oxidative stability but at the expense of compromising the mechanical properties, especially fatigue resistance. Sequential irradiationannealing (X3) improves mechanical properties while preserving the wear properties, although there is a theoretical concern about long-term oxidation in-vivo. Instead of thermal treatment, incorporating antioxidants or sequential irradiation constitutes a balanced environment to create oxidation- and fatigueresistant PE while maintaining its wear characteristics. Despite all newer developments and laboratory studies to date, there is no conclusive evidence that HXLPE would improve clinical outcomes when compared to CPE in TKR. The manufacturers have utilized different PE processing methods, which can influence PE's long-term performance. Surgeons are encouraged to critically look for specific failure mechanisms based on these processing techniques.

\section{Additional Information \\ Disclosures}

Conflicts of interest: In compliance with the ICMJE uniform disclosure form, all authors declare the following: Payment/services info: All authors have declared that no financial support was received from any organization for the submitted work. Financial relationships: All authors have declared that they have no financial relationships at present or within the previous three years with any organizations that might have an interest in the submitted work. Other relationships: All authors have declared that there are no other relationships or activities that could appear to have influenced the submitted work.

\section{References}

1. Purdue PE, Koulouvaris P, Potter HG, Nestor BJ, Sculco TP: The cellular and molecular biology of periprosthetic osteolysis. Clin Orthop Relat Res. 2007, 454:251-61. 10.1097/01.blo.0000238813.95035.1b

2. Fisher J, McEwen HMJ, Tipper JL, et al.: Wear, debris, and biologic activity of cross-linked polyethylene in the knee: benefits and potential concerns. Clin Orthop Relat Res. 2004, 428:114-9. 10.1097/01.blo.0000148783.20469.4c

3. Baumann B, Seufert J, Jakob F, Nöth U, Rolf O, Eulert J, Rader CP: Activation of NF-KB signalling and TNF $\alpha$ expression in THP-1 macrophages by TiAlV- and polyethylene-wear particles. J Orthop Res. 2005, 23:1241-8. 10.1016/j.orthres.2005.02.017.1100230602

4. Julin J, Jämsen E, Puolakka T, Konttinen YT, Moilanen T: Younger age increases the risk of early prosthesis failure following primary total knee replacement for osteoarthritis: a follow-up study of 32,019 total knee replacements in the Finnish Arthroplasty Register. Acta Orthop. 2010, 81:413-9. $10.3109 / 17453674.2010 .501747$

5. Chakravarty R, Elmallah RDK, Cherian JJ, Kurtz SM, Mont MA: Polyethylene wear in knee arthroplasty. J Knee Surg. 2015, 28:370-5. 10.1055/s-0035-1551833

6. Sisko ZW, Teeter MG, Lanting BA, et al.: Current total knee designs: does baseplate roughness or locking mechanism design affect polyethylene backside wear?. Clin Orthop Relat Res. 2017, 475:2970-80. 10.1007/s11999-017-5494-3

7. Essner A, Herrera L, Hughes P, Kester M: The influence of material and design on total knee replacement wear. J Knee Surg. 2011, 24:9-18. 10.1055/s-0031-1275390

8. Kurtz SM: UHMWPE Biomaterials Handbook: Ultra High Molecular Weight Polyethylene in Total Joint Replacement and Medical Devices. Kurtz SM (ed): William Andrew, Massachusetts; 2015.

9. Brach del Prever EM, Bistolfi A, Bracco P, Costa L: UHMWPE for arthroplasty: past or future?. J Orthopaed Traumatol. 2009, 10:1-8. 10.1007/s10195-008-0038-y

10. Costa L, Bracco P, Brach Del Prever EM, Kurtz SM, Gallinaro P: Oxidation and oxidation potential in contemporary packaging for polyethylene total joint replacement components. J Biomed Mater Res B Appl Biomater. 2006, 78:20-6. 10.1002/jbm.b.30454

11. Pruitt LA: Deformation, yielding, fracture and fatigue behavior of conventional and highly cross-linked ultra high molecular weight polyethylene. Biomaterials. 2005, 26:905-15. 10.1016/j.biomaterials.2004.03.022

12. Green TR, Fisher J, Stone M, Wroblewski BM, Ingham E: Polyethylene particles of a 'critical size' are necessary for the induction of cytokines by macrophages in vitro. Biomaterials. 1998, 19:2297-302. 10.1016/S0142-9612(98)00140-9

13. Ingham E, Fisher J: Biological reactions to wear debris in total joint replacement . Proc Inst Mech Eng H. 
2000, 214:21-37. 10.1243/0954411001535219

14. Muratoglu OK, Ruberti J, Melotti S, Spiegelberg SH, Greenbaum ES, Harris WH: Optical analysis of surface changes on early retrievals of highly cross-linked and conventional polyethylene tibial inserts. J Arthroplasty. 2003, 18:42-7. 10.1016/S0883-5403(03)00293-6

15. Diamond OJ, Howard L, Masri B: Five cases of tibial post fracture in posterior stabilized total knee arthroplasty using Prolong highly cross-linked polyethylene. Knee. 2018, 25:657-62. 10.1016/j.knee.2018.05.005

16. Utzschneider S, Harrasser N, Schroeder C, Mazoochian F, Jansson V: Wear of contemporary total knee replacements - a knee simulator study of six current designs. Clin Biomech. 2009, 24:583-8. 10.1016/j.clinbiomech.2009.04.007

17. Sonn KA, Meneghini RM: Early failure of sequentially annealed polyethylene in total knee arthroplasty . Arthroplast Today. 2020, 6:18-22. 10.1016/j.artd.2019.12.005

18. Wang A, Yau SS, Essner A, Herrera L, Manley M, Dumbleton J: A highly crosslinked UHMWPE for CR and PS total knee arthroplasties. J Arthroplasty. 2008, 23:559-66. 10.1016/j.arth.2007.05.007

19. Boyer B, Bordini B, Caputo D, Neri T, Stea S, Toni A: Is cross-linked polyethylene an improvement over conventional ultra-high molecular weight polyethylene in total knee arthroplasty?. J Arthroplasty. 2018, 33:908-14. 10.1016/j.arth.2017.10.005

20. Lambert B, Neut D, van der Veen HC, Bulstra SK: Effects of vitamin E incorporation in polyethylene on oxidative degradation, wear rates, immune response, and infections in total joint arthroplasty: a review of the current literature. Int Orthop. 2019, 43:1549-57. 10.1007/s00264-018-4237-8

21. Chen W, Bichara DA, Suhardi J, Sheng P, Muratoglu OK: Effects of vitamin E-diffused highly cross-linked UHMWPE particles on inflammation, apoptosis and immune response against S. aureus. Biomaterials. 2017, 143:46-56. 10.1016/j.biomaterials.2017.07.028

22. Banche G, Allizond V, Bracco P, et al.: Interplay between surface properties of standard, vitamin E blended and oxidised ultra high molecular weight polyethylene used in total joint replacement and adhesion of Staphylococcus aureus and Escherichia coli. Bone Joint J. 2014, 96:497-501. 10.1302/0301-620X.96B4.32895

23. Oral E, Muratoglu OK: Vitamin E diffused, highly crosslinked UHMWPE: a review . Int Orthop. 2011, 35:21523. 10.1007/s00264-010-1161-y

24. Haider H, Weisenburger JN, Kurtz SM, Rimnac CM, Freedman J, Schroeder DW, Garvin KL: Does vitamin Estabilized ultrahigh-molecular-weight polyethylene address concerns of cross-linked polyethylene in total knee arthroplasty?. J Arthroplasty. 2012, 27:461-9. 10.1016/j.arth.2011.03.024

25. Bichara DA, Malchau E, Sillesen NH, Cakmak S, Nielsen GP, Muratoglu OK: Vitamin E-diffused highly crosslinked UHMWPE particles induce less osteolysis compared to highly cross-linked virgin UHMWPE particles in vivo. J Arthroplasty. 2014, 29:232-7. 10.1016/j.arth.2014.03.044

26. Lambert B, Neut D, van der Veen HC, Bulstra SK: Effects of vitamin E incorporation in polyethylene on oxidative degradation, wear rates, immune response, and infections in total joint arthroplasty: a review of the current literature. Int Orthop. 2019, 43:1549-57. 10.1007/s00264-018-4237-8

27. Bates MD, Mauerhan DR: Early fracture of a vitamin-E-infused, highly cross-linked polyethylene liner after total hip arthroplasty. JBJS Case Connect. 2015, 5:e65. 10.2106/JBJS.CC.N.00157

28. Atwood SA, Van Citters DW, Patten EW, Furmanski J, Ries MD, Pruitt LA: Tradeoffs amongst fatigue, wear, and oxidation resistance of cross-linked ultra-high molecular weight polyethylene. J Mech Behav Biomed Mater. 2011, 4:1033-45. 10.1016/j.jmbbm.2011.03.012

29. Ansari F, Ries MD, Pruitt L: Effect of processing, sterilization and crosslinking on UHMWPE fatigue fracture and fatigue wear mechanisms in joint arthroplasty. J Mech Behav Biomed Mater. 2016, 53:329-40. 10.1016/j.jmbbm.2015.08.026

30. Meneghini RM, Lovro LR, Smits SA, Ireland PH: Highly cross-linked versus conventional polyethylene in posterior-stabilized total knee arthroplasty at a mean 5-year follow-up. J Arthroplasty. 2015, 30:1736-9. 10.1016/j.arth.2015.05.009

31. Iwakiri K, Minoda Y, Kobayashi A, et al.: In vivo comparison of wear particles between highly crosslinked polyethylene and conventional polyethylene in the same design of total knee arthroplasties. J Biomed Mater Res B Appl Biomater. 2009, 91:799-804. 10.1002/jbm.b.31458

32. Meneghini RM, Ireland PH, Bhowmik-Stoker M: Multicenter study of highly cross-linked vs conventional polyethylene in total knee arthroplasty. J Arthroplasty. 2016, 31:809-14. 10.1016/j.arth.2015.10.034

33. Kondo M, Fujii T, Kitagawa H, Tsumura H, Kadoya Y: Arthroscopy for evaluation of polyethylene wear after total knee arthroplasty. J Orthop Sci. 2008, 13:433-7. 10.1007/s00776-008-1258-y

34. Wilhelm SK, Henrichsen JL, Siljander M, Moore D, Karadsheh M: Polyethylene in total knee arthroplasty: where are we now?. J Orthop Surg. 2018, 26:10.1177/2309499018808356

35. De Steiger RN, Muratoglu O, Lorimer M, Cuthbert AR, Graves SE: Lower prosthesis-specific 10-year revision rate with crosslinked than with non-crosslinked polyethylene in primary total knee arthroplasty. Acta Orthop. 2015, 86:721-7. 10.3109/17453674.2015.1065046

36. Bitar D, Parvizi J: Biological response to prosthetic debris . World J Orthop. 2015, 6:172-89. 10.5312/wjo.v6.i2.172

37. Ingham E, Fisher J: Biological reactions to wear debris in total joint replacement . Proc Inst Mech Eng H. 2000, 214:21-37. 10.1243/0954411001535219

38. Liu A, Richards L, Bladen CL, Ingham E, Fisher J, Tipper JL: The biological response to nanometre-sized polymer particles. Acta Biomater. 2015, 23:38-51. 10.1016/j.actbio.2015.05.016

39. Pruitt LA, Ansari F, Kury M, et al.: Clinical trade-offs in cross-linked ultrahigh-molecular-weight polyethylene used in total joint arthroplasty. J Biomed Mater Res B Appl Biomater. 2013, 101:476-84. 10.1002/jbm.b.32887

40. Inacio MCS, Cafri G, Paxton EW, Kurtz SM, Namba RS: Alternative bearings in total knee arthroplasty: risk of early revision compared to traditional bearings: an analysis of 62,177 primary cases. Acta Orthop. 2013, 84:145-52. 10.3109/17453674.2013.784660

41. Paxton EW, Inacio MCS, Kurtz S, Love R, Cafri G, Namba RS: Is there a difference in total knee arthroplasty risk of revision in highly crosslinked versus conventional polyethylene?. Clin Orthop Relat Res. 2015, 


\section{Cureus}

473:999-1008. 10.1007/s11999-014-4046-3

42. Partridge TCJ, Baker PN, Jameson SS, Mason J, Reed MR, Deehan DJ: Conventional versus highly crosslinked polyethylene in primary total knee replacement: a comparison of revision rates using data from the national joint registry for England, Wales, and Northern Ireland. J Bone Joint Surg Am. 2020, 102:119-27. 10.2106/JBJS.19.00031

43. Gioe TJ, Sharma A, Tatman P, Mehle S: Do “premium” joint implants add value?: analysis of high cost joint implants in a community registry. Clin Orthop Relat Res. 2011, 469:48-54. 10.1007/s11999-010-1436-Z

44. Suter LG, Paltiel AD, Rome BN, et al.: Placing a price on medical device innovation: the example of total knee arthroplasty. PLoS One. 2013, 8:e62709. 10.1371/journal.pone.0062709

45. Munir KS, Wen C, Li Y: Carbon nanotubes and graphene as nanoreinforcements in metallic biomaterials: a review. Adv Biosyst. 2019, 3:1800212. 10.1002/adbi.201800212

46. Reddy SK, Kumar S, Varadarajan KM, Marpu PR, Gupta TK, Choosri M: Strain and damage-sensing performance of biocompatible smart CNT/UHMWPE nanocomposites. Mater Sci Eng C. 2018, 92:957-68. 10.1016/j.msec.2018.07.029

47. Puértolas JA, Kurtz SM: Evaluation of carbon nanotubes and graphene as reinforcements for UHMWPEbased composites in arthroplastic applications: a review. J Mech Behav Biomed Mater. 2014, 39:129-45. 10.1016/j.jmbbm.2014.06.013

48. Baena JC, Wu J, Peng Z: Wear performance of UHMWPE and reinforced UHMWPE composites in arthroplasty applications: a review. Lubricants. 2015, 3:413-36. 10.3390/lubricants3020413

49. Chmell MJ, Poss R, Thomas WH, Sledge CB: Early failure of hylamer acetabular inserts due to eccentric wear. J Arthroplasty. 1996, 11:351-3. 10.1016/S0883-5403(96)80093-3 